\title{
Inhibition of Mild Steel Corrosion in Hydrochloric Acid Solution by Leaves of Ziziphus jujuba
}

\author{
Rakesh Kumar Dubey*†, Nitin Gupta**, S. M. Nafees** and Kalpana S.** \\ *Govt. College, Gangapur city-322201, Sawai Madhopur, Rajasthan, India \\ ** Govt. College Kota-324001, Rajasthan, India \\ $\dagger$ Corresponding author: Rakesh Kumar Dubey; rakeshdubeygangapurcity@gmail.com
}

Nat. Env. \& Poll. Tech. Website: www.neptjournal.com

Received: 19-08-2019

Accepted: 18-09-2019

Key Words:

Ziziphus jujuba leaves;

Corrosion;

Langmuir isotherm;

Weight loss method

\begin{abstract}
Weight loss method was used to assess the inhibition of mild steel corrosion in $1 \mathrm{M} \mathrm{HCl}$ solution with aqueous extract of Ziziphus jujuba leaves at 303 to $333 \mathrm{~K}$ temperatures. It was found that Ziziphus jujuba leaves extract retarded the dissolution of mild steel in $1 \mathrm{M} \mathrm{HCl}$ solution. The inhibition efficiency increases with a rise in the concentration of extract and decreased with increase in temperature. Maximum $88.54 \%$ inhibition efficiency was observed at $303 \mathrm{~K}$ and $8 \%(\mathrm{v} / \mathrm{v}$ ) composition of the extract. Adsorption of extract at mild steel surface follows Langmuir adsorption isotherm. Values of Gibbs free energy, variation in inhibition energy with temperature and with activation energy values trend proposed the physisorption. Negative values of Gibbs energy propose the spontaneous process of inhibition process in the extract at studied temperatures.
\end{abstract}

\section{INTRODUCTION}

Steel is widely used alloy in transportation, mechanical and petrochemical industries. However, it suffers from a major problem of corrosion. Corrosion is the degradation of metals and their alloys by an electrochemical reaction and environment. The introduction of corrosion inhibitors is the best way to prevent metallic corrosion, which can save the great economic loss. Most of the corrosion inhibitors are synthetic chemicals which are expansive and hazardous to the environment. Due to the toxicity of chemical corrosion inhibitors, there has been a rise in thrust for the search for green corrosion inhibitors (Al-Sehaibani 2000).

This has provoked the researchers to search for new eco-friendly, low cost, easily available effective corrosion inhibitors to foster green environment and for the sustainability of living beings. Plant products are organic in nature, and contain certain photochemicals including tannins, flavonoids, saponins, amino acids, alkaloids, and pigments which can be extracted by simple and less expensive procedures. Extracts from different parts of the plants have been widely reported as effective and good metal corrosion inhibitors in various corrosive environments.

Literature survey also reveals that various plant extracts have been used as corrosion inhibitors for protection of different metals and their alloys in the last few decades. Extract of fenugreek seeds and leaves (Noor 2008), essential oils of
Mentha spicata, Lavandula multifida, Pulicaria mauritanica (Znini 2012) Azadirachta indica (Sharma 2010), extract of Ananas comosus L. (Ekanem et al. 2010), Embilica officinalis (Saratha et al. 2010), Garcinacola and Cola nitida (Eddy 2010), Nerium olender leaves, Calotropis procera, Ziziphus jujba, etc. In the continuity of above corrosion inhibition studies, the present work has been chosen which indicate studies of corrosion prevention properties of aqueous extract of leaves of Ziziphus jujuba L. for mild steel in 1 $\mathrm{M} \mathrm{HCl}$ solution.

\section{MATERIALS AND METHODS}

Preparation of the extract: The leaves of Ziziphus jujuba plant were taken, washed and air-dried for 6-7 days, crushed and ground mechanically. $20 \mathrm{~g}$ of ground leaves were heated in $200 \mathrm{~mL}$ distilled water for one hour using air condenser at $70^{\circ} \mathrm{C}-80^{\circ} \mathrm{C}$. This extract was left overnight and then filtered and made up to $200 \mathrm{~mL}$ with distilled water for the experiment.

Selection of the steel specimens: Rectangular mild steel specimens of $5 \mathrm{~cm}$ length and $1 \mathrm{~cm}$ diameter were taken and abraded with a series of emery papers, degreased with acetone, washed with distilled water, dried and constant weight was recorded by electronic balance.

Solution preparation: $1 \mathrm{M} \mathrm{HCl}$ solution was prepared by $37 \% \mathrm{HCl}$ using distilled water. The employed concentration 
range of aqueous extract of Ziziphus jujuba leaves (AEZJL) was $1 \%$ to $8 \%(\mathrm{v} / \mathrm{v})$.

Gravimetric measurement: Gravimetric method is a widely used method because of its reliability and simplicity in corrosion inhibition experiments. For each experiment $100 \mathrm{~mL}$ test solution was taken in $250 \mathrm{~mL}$ beaker and a rectangular specimen was immersed in it with plastic thread for one hour.

The experiments were carried out at different temperatures $303,313,323$ to $333 \mathrm{~K}$ in a thermostatic water bath. After one-hour specimens were removed, washed with distilled water, acetone dried and abraded with series of emery papers and then weighed up to constant weight.

\section{RESULTS AND DISCUSSION}

Corrosion rates: Corrosion rates were calculated by the following equation (1) (Behpour et al. 2011, Umoren et al. 2016).

$$
\mathrm{CR}\left(\mathrm{g} \mathrm{cm}^{-2} \mathrm{~min}^{-1}\right)=\left(\mathrm{W}_{1}-\mathrm{W}_{2} / \mathrm{At}\right)
$$

Where, $\mathrm{CR}$ is corrosion rate, $\mathrm{W}_{1}$ is weight loss of mild steel specimen without inhibitor and $\mathrm{W}_{2}$ is weight loss of mild steel specimen with inhibitor, $\mathrm{A}$ is the area of MS specimen and $\mathrm{t}$ is immersion time. Table 1 shows that corrosion rates of mild steel decrease with increase in the concentration of Ziziphus jujuba leaves inhibitor at all studied temperatures. This could be subjected to the adsorption of the phyto-constituents of inhibitor molecules with the increase in the concentration of inhibitor. The corrosion rate obeys Arrhenius type reaction, as it increases with the rise in temperature (Noor 2007).

Inhibition efficiency: From the obtained corrosion rates, inhibition efficiencies were calculated by using equation (2) (Behpour et al. 2011, Umoren et al. 2016).

$$
\mathrm{IE} \%=\frac{C R_{\text {blank }}-C R_{\text {inh }}}{C \boldsymbol{R}_{\text {blank }}} \times 100
$$

Where, $\mathrm{CR}_{\text {blank }}$ is the corrosion rate in the absence of inhibitor and $\mathrm{CR}_{\mathrm{inh}}$ is the corrosion rate in the presence of inhibitor. Mild steel corrosion rates in $1 \mathrm{M} \mathrm{HCl}$ solution with Ziziphus jujuba leaves are given in Table 1. Data in Table 2 and Fig. 1 show that \% IE increase with the rise in extract concentration, which is an indication of an increase in the number of components of extract adsorbed on mild steel surface, which block the active sites of metal from acid attack and protect the metallic corrosion (Obi-Egbedi et al. 2012). Further, the decrease in \% IE with the rise in temperature suggests electrostatic interaction (physical adsorption) of the extract molecules on the mild steel surface. This further indicates desorption of adsorbed inhibitor species at higher temperatures and metal dissolution takes place (Yadav et al. 2014). $88.54 \%$ inhibition efficiency is observed at $8 \%(\mathrm{v} / \mathrm{v})$ concentration of inhibitor.

Table 1: Mild steel corrosion rates in $1 \mathrm{M} \mathrm{HCl}$ solution in the absence and presence of different concentrations of Ziziphus jujuba leaves at different temperatures.

\begin{tabular}{|lllll|}
\hline \multirow{2}{*}{$\mathrm{C}_{\text {inh }}$ in $(\mathrm{v} / \mathrm{v}) \%$} & \multicolumn{3}{c|}{$\mathrm{CR} \times 10^{-3}\left(\mathrm{~g} \mathrm{~cm}^{-2} \mathrm{~min}^{-1}\right)$} \\
\cline { 2 - 5 } & $303 \mathrm{~K}$ & $313 \mathrm{~K}$ & $323 \mathrm{~K}$ & $333 \mathrm{~K}$ \\
\hline 0 & 0.96 & 1.53 & 2.19 & 2.76 \\
1 & 0.73 & 1.14 & 2.03 & 2.64 \\
2 & 0.57 & 0.87 & 1.94 & 2.59 \\
3 & 0.39 & 0.73 & 1.83 & 2.53 \\
5 & 0.27 & 0.57 & 1.74 & 2.47 \\
8 & 0.11 & 0.39 & 1.58 & 2.38 \\
\hline
\end{tabular}

Table 2: Inhibition efficiencies of Ziziphus jujuba leaves at different concentrations and temperatures in solutions of $1 \mathrm{M} \mathrm{HCl}$.

\begin{tabular}{|lllll|}
\hline \multirow{2}{*}{$\mathrm{C}_{\text {inh }}$ in $(\mathrm{v} / \mathrm{v}) \%$} & $303 \mathrm{~K}$ & $313 \mathrm{~K}$ & $\mathrm{IE}(\%)$ & $333 \mathrm{~K}$ \\
\hline 1 & 23.96 & 25.49 & $323 \mathrm{~K}$ & 4.35 \\
2 & 40.63 & 43.14 & 7.31 & 6.16 \\
3 & 59.38 & 52.29 & 11.42 & 8.33 \\
5 & 71.88 & 62.75 & 16.44 & 10.51 \\
8 & 88.54 & 74.51 & 20.55 & 13.77 \\
\hline
\end{tabular}




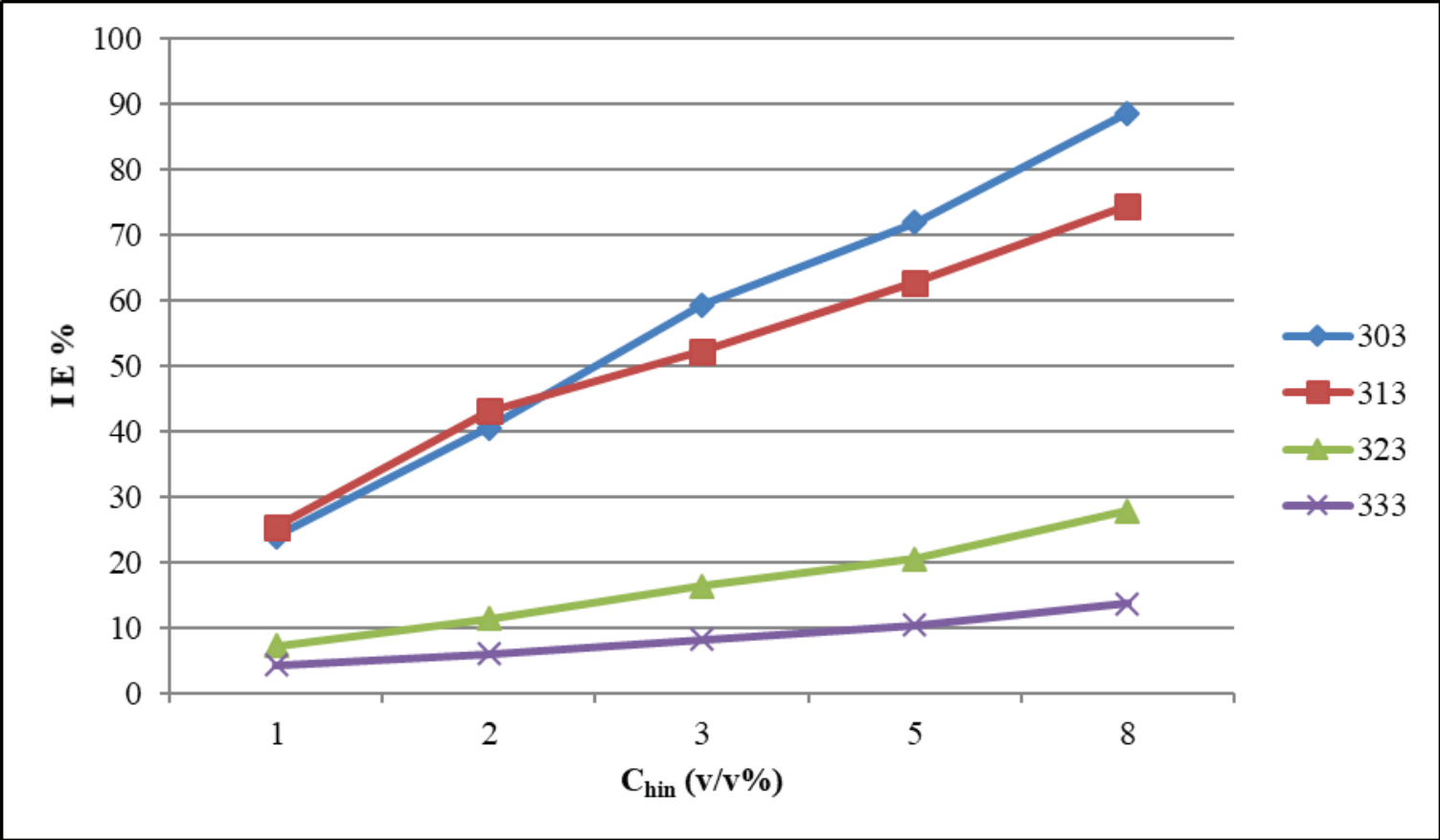

Fig. 1: Variation in \% IE for mild steel corrosion in $1 \mathrm{M} \mathrm{HCl}$ at different concentration of Ziziphus jujuba leaves at different temperatures.

Kinetic parameters: Assuming that corrosion rates of steel specimens against the concentration of inhibitor obey kinetic relationship as equation (3) (Noor 2007, Khamis 1990).

$$
\log \mathrm{CR}=\log \mathrm{K}+\mathrm{B} \log \mathrm{C}_{\text {inh }}
$$

Where, $\mathrm{K}$ is rate constant and equal to $\mathrm{CR}$ when inhibitor concentration is unity. $\mathrm{B}$ is reaction constant which is the measure of inhibitor effectiveness and $\mathrm{C}_{\mathrm{inh}}$ is the concentration $\mathrm{v} / \mathrm{v} \%(\mathrm{~mL} / 100 \mathrm{~mL})$ of Ziziphus jujuba leaves. Fig. 2 represents the plot between $\log \mathrm{CR}$ and $\log \mathrm{C}_{\text {inh }}$ values at different studied temperatures. $\mathrm{B}$ and $\mathrm{K}$ were calculated by the slope and intercept of straight lines obtained in Fig. 2. The obtained results are summarized in Table 3 which can be discussed as follows (Noor 2007). Negative values of B indicate that the corrosion rate is inversely proportional to the concentration of inhibitor. In other words, the corrosion rates decrease with increase in the concentration of inhibitor species.

The high negative values of B reflect the good inhibitive property of inhibitor. The high negative value of $\mathrm{B}$ was observed as a steep slope in the graph (Fig. 2). Value of B is high at lower temperatures, indicating that inhibitive species are more effective at comparatively lower temperatures. The increase in $\mathrm{K}$ values with increase in temperature, indicating the increase in corrosion rates with temperatures.

Thermodynamic and activation parameters: Thermodynamic and activation parameters like apparent activation energy $\mathrm{E}_{\text {act }}$, enthalpy of activation $\Delta \mathrm{H}^{*}$, and the entropy of activation $\Delta S^{*}$ were calculated for the steel dissolution process. Activation energies $\mathrm{E}_{\text {act }}$ were calculated by following Arrhenius equation (4) (Umoren et al. 2016, Yadav et al. 2014)

$$
\left.\log \mathrm{CR}=\log \mathrm{A}-\frac{\text { Eact }}{2.303 R T}\right)
$$

Where, $\mathrm{A}$ is Arrhenius pre-exponential factor, $\mathrm{E}_{\text {act }}$ is the activation energy, $\mathrm{R}$ is the universal gas constant, $\mathrm{T}$ is the absolute temperature. The slope of $\log \mathrm{CR}$ vs $1 / \mathrm{T}$ in Fig. 3 gives the values of activation energies at studied concentrations. Table 3 represents the calculated data of activation energies. The values of activation energies in the presence of inhibitor were found higher than in uninhibited solution. This indicates the formation of a higher energy barrier in corrosion reaction by inhibitor molecules. The increase in $\mathrm{E}_{\text {act }}$ for corrosion process in inhibitor solution further interpreted as physical adsorption of inhibitor species on mild steel surface (Popova et al. 2003). Besides this, according to Damaskin (1971), the value of activation energy lesser than $80 \mathrm{~kJ} / \mathrm{mol}$ and even smaller than $5 \mathrm{~kJ} / \mathrm{mol}$ represents physical adsorption. This assertion supports the experimental results obtained in the present study. The values of enthalpy of activation $\Delta \mathrm{H}^{*}$ and entropy of activation $\Delta \mathrm{S}^{*}$ were calculated by following the transition state as in equation (5) (Umoren et al. 2016, Yadav et al. 2014). 


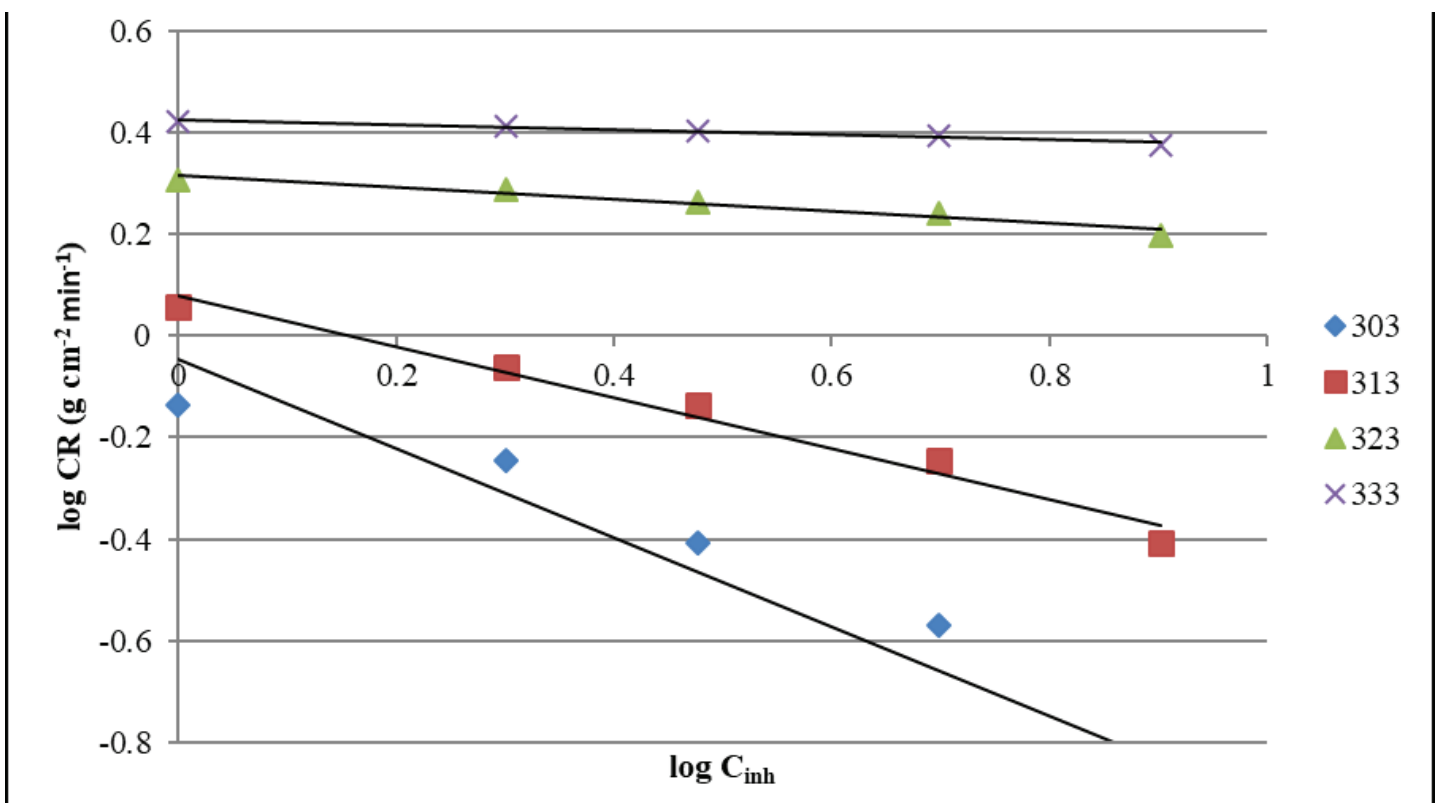

Fig. 2: Variation in $\log \mathrm{CR}$ with $\log \mathrm{C}_{\mathrm{inh}}$ for mild steel corrosion in $1 \mathrm{M} \mathrm{HCl}$ in the presence of different concentrations of Ziziphus jujuba leaves at different temperatures.

Table 3: Kinetic parameters for mild steel corrosion in 1M HCL solution with Ziziphus jujuba leaves.

\begin{tabular}{|lll|}
\hline \multirow{2}{*}{ Temperature $(\mathrm{K})$} & \multicolumn{2}{c|}{ Kinetic Parameters } \\
\cline { 2 - 3 } & $\mathrm{B}$ & $\mathrm{K} \times 10^{-3}\left(\mathrm{~g} \mathrm{~cm}^{-2} \mathrm{~min}^{-1}\right)$ \\
\hline $303 \mathrm{~K}$ & -0.049 & 2.660725 \\
$313 \mathrm{~K}$ & -0.118 & 2.06538 \\
$323 \mathrm{~K}$ & -0.502 & 1.202264 \\
$333 \mathrm{~K}$ & -0.876 & 1.111732 \\
\hline
\end{tabular}

$\log _{(\mathrm{CR} / \mathrm{T})}=\left[\log _{(\mathrm{R} / \mathrm{Nh})}+(\Delta \mathrm{S} * / 2.303 \mathrm{R}-(\Delta \mathrm{H} * / 2.303 \mathrm{RT})]\right.$

Where, $\mathrm{h}$ is Planck's constant, $\mathrm{N}$ is Avogadro number, $\mathrm{R}$ is the gas constant. A plot of $\log (\mathrm{CR} / \mathrm{T})$ vs $1 / \mathrm{T}$ gave a straight line with the slope of $\left(-\Delta H^{*} / 2.303 \mathrm{R}\right)$ and intercept of $[(\log \mathrm{R} / \mathrm{Nh})+(\Delta \mathrm{S} * / 2.303 \mathrm{R})]$ from which the values of $\Delta \mathrm{H}^{*}$ and $\Delta \mathrm{S}^{*}$ were calculated (Fig. 4). These values are tabulated in Table 4 . Values of $\Delta \mathrm{H}^{*}$ were found positive. Positive values indicate endothermic nature of steel dissolution process (Yadav et al. 2014, Behpour et al. 2011) Endothermic process further indicates that mild steel dissolution reduces at lower temperatures and increases with increase in temperature. Negative values of $\Delta S^{*}$ are indicative of the formation of an activated complex in the rate-determining step, which represents association rather than dissociation step, meaning the decrease in disorder takes place on going from reactants to activated complex. (Gomma \& Wahdan 1995). It is also observed from data in Table 4 that $E_{\text {act }}$ and
$\Delta \mathrm{H}^{*}$ vary in the same manner. Values of both $\mathrm{E}_{\text {act }}$ and $\Delta \mathrm{H}^{*}$ increase with the increase in the concentration of inhibitor, suggesting that energy barrier increases with increase in inhibitor concentration. This means that corrosion reaction will further be pushed to surface sites that are characterized by progressively higher values of $\mathrm{E}_{\mathrm{act}}$ as the concentration of inhibitor becomes greater (Solmaz et al. 2008).

The values of activation energy were found larger than corresponding values of enthalpy of activation, indicate the involvement of a gaseous reaction, simply hydrogen evolution in the corrosion process, associated with a decrease in total reaction volume (Noor 2007).

Adsorption isotherm and Gibbs energy: The nature of adsorption can be explained by understanding the process at metal/electrolyte interface. Further, to understand the nature of adsorption, obtained surface coverage were fitted in different adsorption isotherms. Langmuir adsorption isotherm was the best fit. The mathematical expressions for Langmuir 


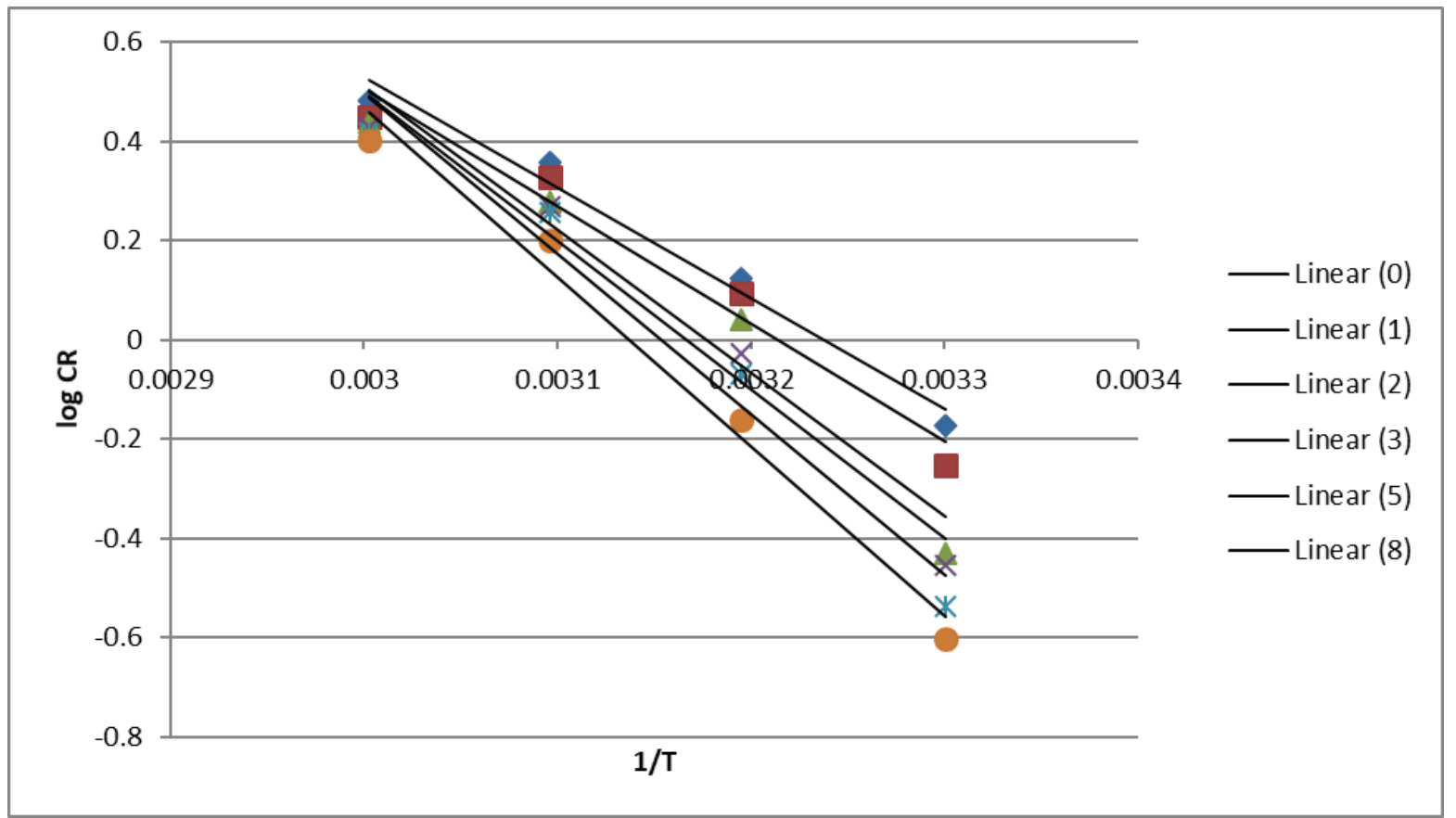

Fig. 3: Arrhenius plots for mild steel corrosion in $1 \mathrm{M} \mathrm{HCl}$ in the absence and presence of the different concentrations of Ziziphus jujuba leaves.

Table 4: Activation and thermodynamic parameters for mild steel corrosion in $1 \mathrm{M} \mathrm{HCl}$ solution with Ziziphus jujuba leaves.

\begin{tabular}{|c|c|c|c|c|}
\hline $\mathrm{C}_{\mathrm{inh}}$ in $(\mathrm{v} / \mathrm{v}) \%$ & $\mathrm{E}_{\mathrm{act}}(\mathrm{kJ} / \mathrm{mol})$ & $\Delta \mathrm{H}^{*}(\mathrm{~kJ} / \mathrm{mol})$ & $\Delta \mathrm{s}^{*}$ & $(\mathrm{~J} / \mathrm{mol} / \mathrm{K})$ \\
\hline 0.0 & 29.68 & 27.12 & -200.82 & \\
\hline 1.0 & 37.26 & 34.76 & -179.88 & \\
\hline 2.0 & 44.86 & 42.36 & -175.67 & \\
\hline 3.0 & 54.89 & 52.42 & -162.88 & \\
\hline 5.0 & 65.23 & 62.77 & -149.57 & \\
\hline 8.0 & 89.51 & 87.08 & -117.92 & \\
\hline
\end{tabular}

adsorption isotherm can be expressed by the equation (6) (Fragoza-Mar et al. 2012, Quartarone et al. 2012, Vasudha et al. 2013).

$$
\frac{c}{\boldsymbol{\theta}}=\frac{1}{\text { Kads }}+\mathrm{C}_{\mathrm{inh}}
$$

Rearranging the above equation (6) we get

$$
\begin{gathered}
\frac{\boldsymbol{\theta}}{\mathbf{1 - \boldsymbol { \theta }}}=\mathrm{K}_{\mathrm{ads}} \mathrm{C}_{\mathrm{inh}} \\
\log \left(\frac{\boldsymbol{\theta}}{\mathbf{1 - \boldsymbol { \theta }}}\right)=\log \mathrm{K}_{\mathrm{ads}}+\log \mathrm{C}_{\mathrm{inh}}
\end{gathered}
$$

Where, $\mathrm{K}_{\mathrm{ads}}$ is the equilibrium constant of adsorption, $\theta$ is the surface coverage, $(1-\theta)$ is the uncovered surface, $C_{i n h}$ is the concentration of inhibitor. Values of $\mathrm{K}_{\mathrm{ads}}$ were calculated from the intercept of Langmuir adsorption isotherm drawn according to the equation (8) between $\log (\theta / 1-\theta)$ and $\log$ $\mathrm{C}_{\text {inh }}$ (Fig. 5). The value of $\mathrm{K}_{\mathrm{ads}}$ obtained from Langmuir adsorption isotherm is related to Gibbs energy according to the equation (9) (Noor 2007).

$$
\mathrm{K}_{\mathrm{ads}}=1 / \mathrm{C}_{\mathrm{H} 2 \mathrm{O}} \exp ^{(-\Delta \mathrm{G} / \mathrm{RT})}
$$

It can be written as:

$$
\Delta \mathrm{G}_{\mathrm{ads}}=-2.303 \mathrm{RT} \log \left(\mathrm{K}_{\mathrm{ads}} \cdot \mathrm{CH}_{2} \mathrm{O}\right)
$$

Where, $\mathrm{CH}_{2} \mathrm{O}$ is the concentration of water in $(\mathrm{mL} / \mathrm{L})$ at metal/solution interface, $\mathrm{R}$ is the universal gas constant and $\mathrm{T}$ is the absolute temperature. The values of $\Delta \mathrm{G}_{\mathrm{ads}}$ were tabulated in Table 5. Obtained values of Gibbs energy were 


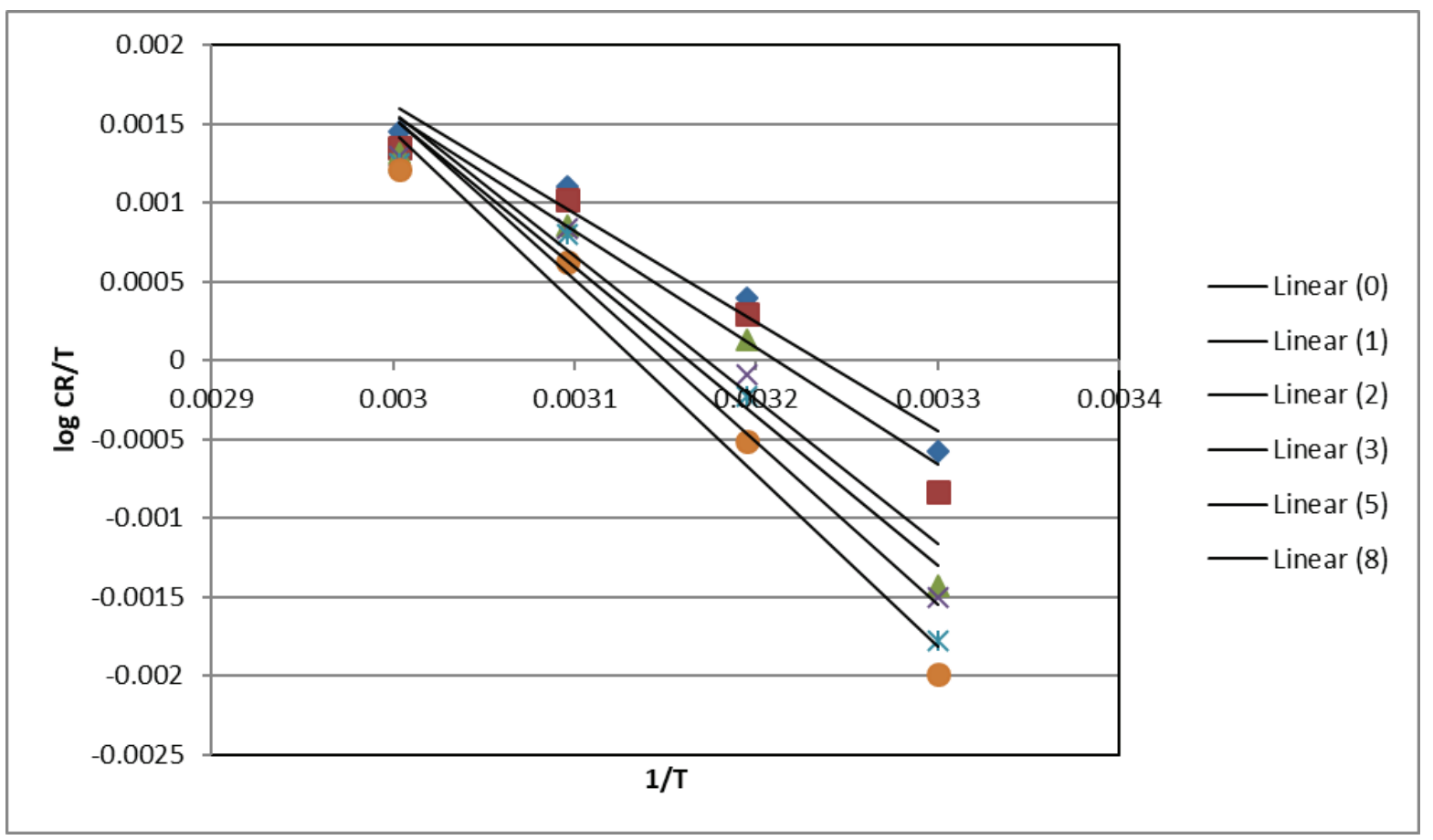

Fig. 4: Transition-state plots for mild steel corrosion in $1 \mathrm{M} \mathrm{HCl}$ in the absence and presence of the different concentrations of Ziziphus jujuba leaves.

plotted against temperature as per the basic equation (11) (El-Awady et al. 1992).

$$
\Delta \mathrm{G}_{\mathrm{ads}}=\Delta \mathrm{H}_{\mathrm{ads}}-\mathrm{T} \Delta \mathrm{S}_{\mathrm{ads}}
$$

The intercept of the graph between $\Delta \mathrm{G}_{\text {ads }}$ vs $\mathrm{T}$ in Fig. 6 gives the value of $\Delta \mathrm{H}_{\mathrm{ads}}$ and by putting the value of intercept in equation (11) values of $\Delta \mathrm{S}_{\mathrm{ads}}$ were obtained. These obtained adsorption parameters, i.e. Gibbs free energy of adsorption $\left(\Delta \mathrm{G}_{\mathrm{ads}}\right)$, enthalpy of adsorption $\left(\Delta \mathrm{H}_{\mathrm{ads}}\right)$ and entropy of adsorption $\left(\Delta \mathrm{S}_{\mathrm{ads}}\right)$ are listed in Table 5. $\Delta \mathrm{G}_{\mathrm{ads}}$ values have been found negative at all studied temperatures indicating spontaneous adsorption process of inhibitor molecules on the metal surface (Behpour 2011). Generally, values of $\Delta \mathrm{G}_{\mathrm{ads}}$ up to $-20 \mathrm{KJ} / \mathrm{mol}$ are consistent with electrostatic interactions (physical adsorption) between charged molecules and charged metal surface and values up to -40 $\mathrm{KJ} / \mathrm{mol}$ or higher involve charge sharing or transfer from inhibitor molecules to metal surface to form the coordinate type of bond (chemical adsorption) (Bouklah et al. 2006). The obtained values of $\Delta \mathrm{G}_{\mathrm{ads}}$ were found less than $-20 \mathrm{~kJ} /$ mol indicated physical adsorption of inhibitor molecules. It has been observed that adsorption of negatively charged species is facilitated due to the positively charged metal. But positively charged species can also be adsorbed and protect the positively charged metal surface acting with a negatively charged intermediate such as acid anions, adsorbed on the metal surface (Popova et al. 2003). Values of $\Delta \mathrm{H}_{\text {ads }}$ have been found negative indicating the exothermic adsorption process ( $\mathrm{Li}$ et al. 2010, Li et al. 2009), which further indicates lower \% IE at higher temperatures, due to desorption of inhibitor molecules. The exothermic process is attributed to either physical or chemical adsorption or the mixture of both (Bentiss et al. 2005). In the exothermic process, values of $\Delta \mathrm{H}_{\text {ads }}$ predict physisorption or chemisorption. For physisorption, the values of $\Delta \mathrm{H}_{\mathrm{ads}}$ are lower than $40 \mathrm{~kJ} /$ mol, while for chemisorption it approaches to $100 \mathrm{~kJ} / \mathrm{mol}$ (Benabdellah et al. 2007) Values of $\Delta \mathrm{H}_{\text {ads }}$ in Table 5 indicate physisorption. Negative values of $\Delta \mathrm{S}_{\mathrm{ads}}$ indicate a decrease in entropy of adsorption process.

This behaviour can be explained as follows: Before the adsorption of inhibitor molecules on to mild steel surface, they might freely move in bulk solution (inhibitor molecules were chaotic). But with the process of adsorption, inhibitor molecules were orderly adsorbed on to the steel surface, as a result, decrease in entropy is observed ( $\mathrm{Li}$ et al. 2010) A more interesting behaviour is observed in Table 5 that negative $\Delta \mathrm{H}_{\text {ads }}$ value is accompanied with negative $\Delta \mathrm{S}_{\text {ads }}$ value. This further agrees that when the adsorption is an exothermic process, it must be accompanied by a decrease in the entropy change and vice versa (Obi-Egbedi et al. 2012). The obtained positive values of $\Delta \mathrm{S}_{\mathrm{ads}}$ are the algebraic sum of the 


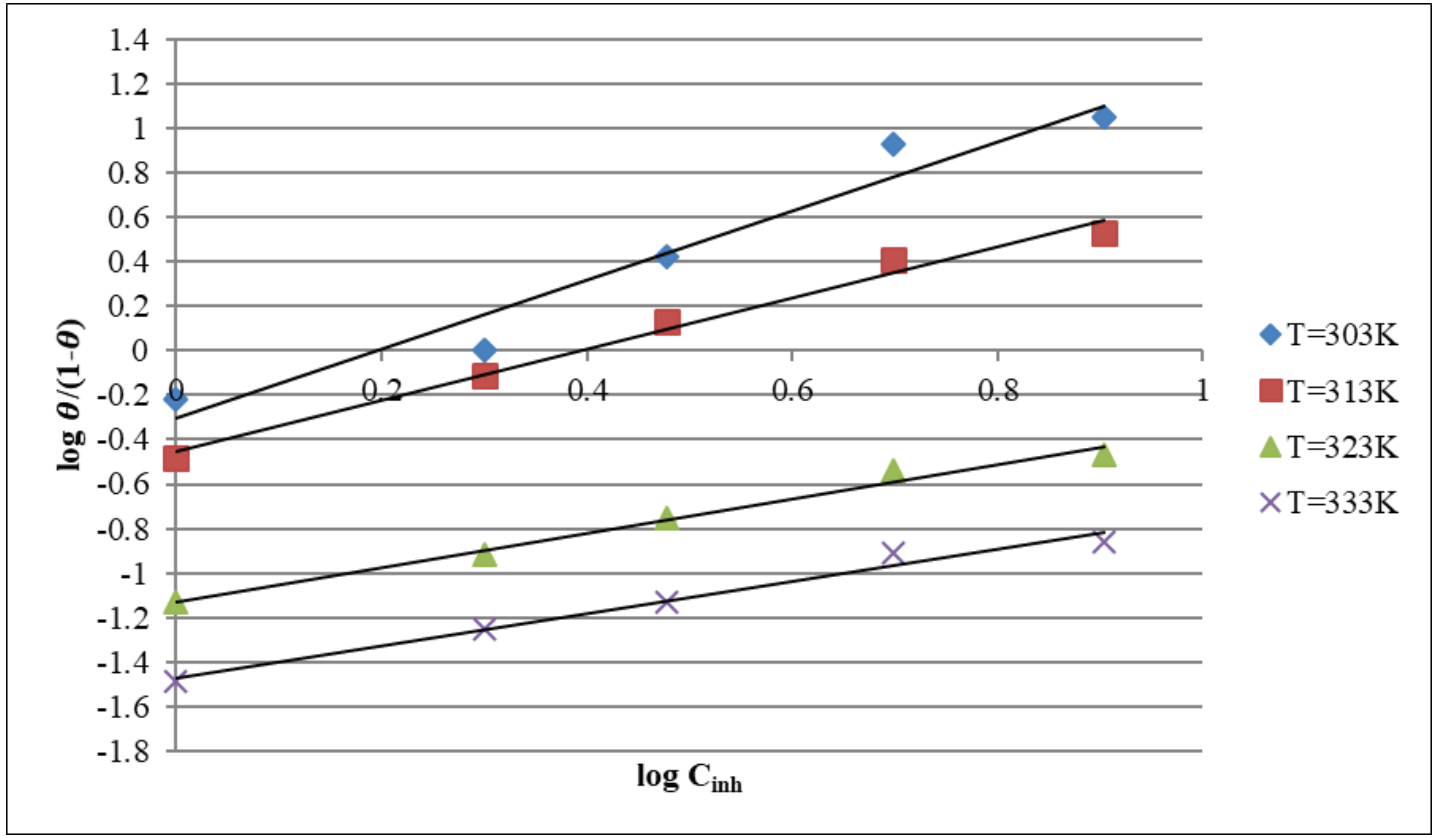

Fig. 5: Langmuir adsorption isotherms of Ziziphus jujuba leaves on mild steel surface in $1 \mathrm{M} \mathrm{HCl}$ at different temperatures.

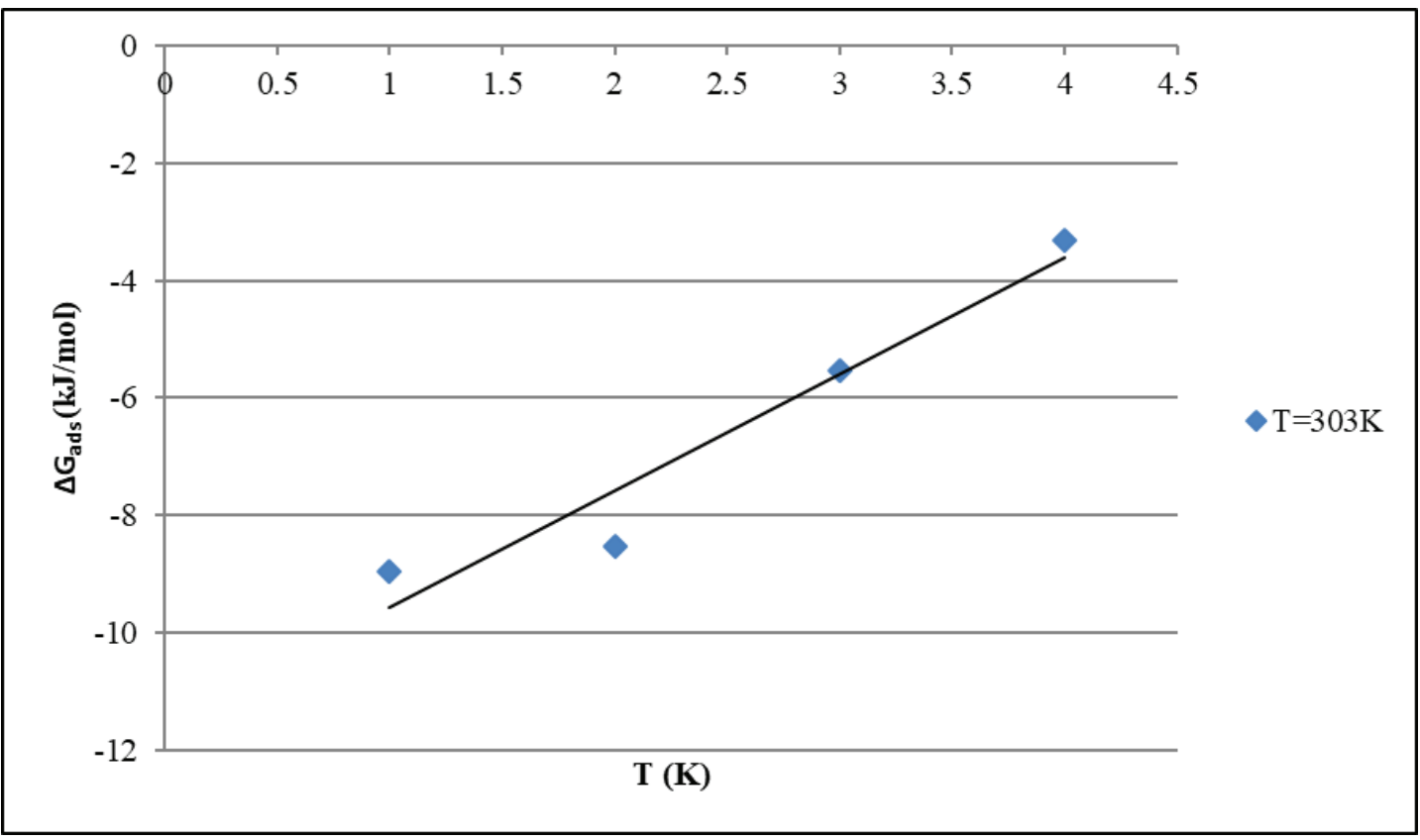

Fig. 6: The Variation of $\Delta \mathrm{G}_{\mathrm{ads}}(\mathrm{kJ} / \mathrm{mol})$ with $\mathrm{T}(\mathrm{K})$ for mild steel corrosion in $1 \mathrm{M} \mathrm{HCl}$ solution with Ziziphus jujuba leaves. 
Table 5: Adsorption parameters for mild steel corrosion in $1 \mathrm{M} \mathrm{HCl}$ solution with Ziziphus jujuba leaves.

\begin{tabular}{|c|c|c|c|c|c|}
\hline Temperature (K) & $\Delta \mathrm{G}_{\mathrm{ads}}(\mathrm{kJ} / \mathrm{mol})$ & $\Delta \mathrm{H}_{\mathrm{ads}}$ & $(\mathrm{kJ} / \mathrm{mol})$ & $\Delta \mathrm{S}_{\mathrm{ads}}$ & $(\mathrm{J} / \mathrm{mol} / \mathrm{K})$ \\
\hline $303 \mathrm{~K}$ & -8.96765 & \multirow{4}{*}{-69.94} & & -201.229 & \\
\hline $313 \mathrm{~K}$ & -8.52646 & & & -196.209 & \\
\hline $323 \mathrm{~K}$ & -5.52726 & & & -199.42 & \\
\hline $333 \mathrm{~K}$ & -3.32651 & & & -200.041 & \\
\hline
\end{tabular}

adsorption of organic molecules and the desorption of water molecules (Li et al. 2009, Kumar et al. 2004). Therefore, the positive values of entropy of adsorption are the result of the substitution process, which can be attributed to the rise in the solvent entropy and more positive water desorption entropy (Badiea \& Mohana 2009).

\section{CONCLUSIONS}

1. The results showed that Ziziphus jujuba leaves are good corrosion inhibitor for mild steel in $1 \mathrm{M} \mathrm{HCl}$ solution under as permitted conditions denoted.

2. Corrosion rates increase with the increase in temperature and decrease with increase in inhibitor concentration.

3. Inhibition efficiencies increases at lower temperature suggest the physisorption process of inhibitor on the mild steel surface.

4. Apparent activation energy increases with increase in inhibitor concentrations also suggests physisorption.

5. Enthalpy of adsorption comes out to be negative and lower than $40 \mathrm{~kJ} / \mathrm{mol}$, which shows exothermic and physical adsorption process of inhibitor.

6. The values of Gibbs free energies calculated were negative showing spontaneity of corrosion inhibition process of mild steel in $1 \mathrm{M} \mathrm{HCl}$ in Ziziphus jujuba leaves.

\section{ACKNOWLEDGEMENT}

The authors are thankful to the Head of Chemistry Department and Principal, Government College, Kota for providing necessary laboratory facilities.

\section{REFERENCES}

Al-Sehaibani, H. 2000. Evaluation of extracts of henna leaves as environmentally friendly corrosion inhibitors for metals. Materialwissenschaft und Werkstofftechnik: Materials Science and Engineering Technology, 31(12), pp.1060-1063.

Badiea, A.M. and Mohana, K.N. 2009. Effect of temperature and fluid velocity on corrosion mechanism of low carbon steel in presence of 2-hydrazino-4,7-dimethylbenzothiazole in industrial water medium. Corrosion Science, 51: 2231-2241.

Behpour, M., Ghoreishi, S.M., Khayatkashani, M. and Soltani, N. 2011. The effect of two oleo gum resin exudate from Ferula assafoetida and
Dorema ammoniacum on mild steel corrosion in acidic media. Corrosion Science, 53: 2489-2501.

Benabdellah, M., Touzani, R., Dafali, A., Hammouti, B. and El Kadiri, S. 2007. Ruthenium-ligand complex, an efficient inhibitor of steel corrosion in H3PO4 media. Materials Letters, 61: 1197-1204.

Bentiss, F., Lebrini, M. and Lagrenée, M. 2005. Thermodynamic characterization of metal dissolution and inhibitor adsorption processes in mild steel/2,5-bis(n-thienyl)-1,3,4- thiadiazoles/hydrochloric acid system. Corrosion Science, 47: 2915-2931.

Bouklah, M., Benchat, N., Hammouti, B., Aouniti, A. and Kertit, S. 2006. Thermodynamic characterization of steel corrosion and inhibitor adsorption of pyridazine compounds in $0.5 \mathrm{M} \mathrm{H} 2 \mathrm{SO} 4$. Materials Letters, 60(15): 1901-1905.

Damaskin, B.B. 1971. Adsorption of Organic Compounds on Electrodes, Plenum Press, New York, 221.

Eddy, N.O. 2010. Adsorption and inhibitive properties of ethanol extract of Garcinia kola and Cola nitida for the corrosion of mild steel in $\mathrm{H}_{2} \mathrm{SO}_{4}$. Pigment and Resin Technology, 39: 348-354.

Ekanem, U.F., Umoren, S.A., Udousoro, I.I. and Udoh, A.P. 2010. Inhibition of mild steel corrosion in $\mathrm{HCl}$ using pineapple leaves (Ananas comosus L.) extract. J. Mater. Sci., 45: 5558-5566.

El-Awady, A.A., Abd-El-Nabey, B.A. and Aziz, S.G. 1992. Kinetic-thermodynamic and adsorption isotherms analysis for the inhibition of acid corrosion of steel by cyclic and open chain amines. Journal of Electrochemical Society, 139(8): 2149-2154.

Fragoza-Mar, L., Olivares-Xometl, O., Domínguez-Aguilar, M.A., Flores, E.A., Arellanes- Lozada P. and Jiménez-Cruz F. 2012. Corrosion inhibitor activity of 1,3-diketone malonates for mild steel in aqueous hydrochloric acid solution. Corrosion Science, 61: 171-184.

Gomma, G.K. and Wahdan, M.H. 1995. Schiff bases as corrosion inhibitors for aluminium in hydrochloric acid solution. Materials Chemistry and Physics, 39(3): 209-213.

Khamis, E. 1990. The effect of temperature on the acidic dissolution of steel in the presence of inhibitors. Corrosion (NACE), 46(6): 476-484.

Kumar, E. T., Vishwanathan, S. and Udayabhanu, G. 2004. Synergistic effects of formaldehyde and alcoholic extract of plant leaves for protection of $\mathrm{N} 80$ steel in $15 \% \mathrm{HCl}$. Corrosion Engineering Science Technology, 39: 327-332.

Li, X., Deng, S. and Fu, H. 2010. Adsorption and inhibition effect of vanillin on cold rolled steel in $3.0 \mathrm{M} \mathrm{H}_{3} \mathrm{PO}_{4}$. Progress in Organic Coatings, 67(4): 420-426.

Li, X., Deng, S., Fu, H. and Mu, G. 2009. Inhibition effect of 6-benzylaminopurine on the corrosion of cold rolled steel in $\mathrm{H}_{2} \mathrm{SO}_{4}$ solution, Corrosion Science, 51: 620-634.

Noor, E.A. 2007. Temperature effects on the corrosion inhibition of mild steel in acidic solutions by aqueous extract of fenugreek leaves. International Journal of Electrochemical Science, 2: 996- 1017.

Noor, E.A. 2008. Comparative study on the corrosion inhibition of mild steel by aqueous extract of fenugreek seeds and leaves in acidic solutions. Journal of Engineering and Applied Sciences, 3(1): 23-30.

Obi-Egbedi, N.O., Obot I.B. and Umoren, S.A. 2012. Spondias mombin L. as a green corrosion inhibitor for aluminium in sulphuric acid: Correlation between inhibitive effect and electronic properties of extracts 
major constituents using density functional theory. Arabian Journal of Chemistry, 5: 361-373.

Popova, A., Sokolova, E., Raicheva, S. and Christov, M. 2003. AC and DC study of the temperature effect on mild steel corrosion in acid media in the presence of benzimidazole derivatives. Corrosion Science, 45(1): 33-58.

Quartarone, G., Ronchin, L., Vavasori, A., Tortato, C. and Bonaldo, L. 2012. Inhibitive action of gramine towards corrosion of mild steel in deaerated 1.0 M hydrochloric acid solutions. Corrosion Science, 64: 82-89.

Saratha, R. and Vasudha, V.G. 2010. Emblica officinalis (Indian Gooseberry) leaves extract as corrosion inhibitor for mild steel in $1 \mathrm{~N} \mathrm{HCl}$ medium. European Journal of Chemistry, 7: 677-684.

Sharma, R.K., Mudhoo, A., Jain, G. and Sharma, J. 2010. Corrosion inhibition and adsorption properties of Azadirachta indica mature leaves extract as green inhibitor for mild steel in $\mathrm{HNO}_{3}$. Green Chemistry Letters and Reviews, 3: 7-15.

Solmaz, R., Kardas, G., Culha, M., Yazıc1, B. and Erbil, M. 2008. Investi- gation of adsorption and inhibitive effect of 2-mercaptothiazoline on corrosion of mild steel in hydrochloric acid media. Electrochimica Acta, 53(20): 5941-5952.

Umoren, S.A., Eduok, U.M., Solomon, M.M. and Udoh, A.P. 2016. Corrosion inhibition by leaves and stem extracts of Sida acuta for mild steel in $1 \mathrm{M} \mathrm{H}_{2} \mathrm{SO}_{4}$ solutions investigated by chemical and spectroscopic techniques. Arabian Journal of Chemistry, 9: S209-S224.

Vasudha, V.G. and Shanmuga Priya, K. 2013. Polyalthia longifolia as a corrosion inhibitor for mild steel in $\mathrm{HCl}$ solution. Research Journal of Chemical Sciences, 3(1): 21-26.

Yadav, M., Sushil Kumar, Bahadur, I. and Ramjugernath, D. 2014. Corrosion inhibitive effect of synthesized thiourea derivatives on mild steel in a $15 \% \mathrm{HCl}$ solution. International Journal of Electrochemical Science, 9: 6529-6550.

Znini, M., Paolini, J., Majidi, L., Desjobert, J.M., Costa, J., Lahhit, N. and Bouyanzer, A. 2012. Evaluation of the inhibitive effect of essential oil of Lavandula multifida $\mathrm{L}$. on the corrosion behaviour of C38 steel in $0.5 \mathrm{M}$ $\mathrm{H}_{2} \mathrm{SO}_{4}$ medium. Research on Chemical Intermediates, 38(2): 669-683. 